\title{
Geriatric Psychology and Prosthodontic Patient
}

\author{
${ }^{1}$ Laxman Rao Polsani, ${ }^{2}$ Ajay Kumar G, ${ }^{3}$ Githanjali M, ${ }^{4}$ Anjana Raut \\ ${ }^{1}$ Professor, Department of Prosthodontics, Army College of Dental Sciences, Andhra Pradesh, India \\ ${ }^{2}$ Associate Professor, Department of Prosthodontics, Army College of Dental Sciences, Andhra Pradesh, India \\ ${ }^{3}$ Reader, Department of Prosthodontics, Army College of Dental Sciences, Andhra Pradesh, India \\ ${ }^{4}$ Senior Lecturer, Department of Prosthodontics, Army College of Dental Sciences, Andhra Pradesh, India
}

\begin{abstract}
Correspondence: Anjana Raut, Senior Lecturer, Department of Prosthodontics, Army College of Dental Sciences, Andhra Pradesh India, e-mail:dranjana_acds@yahoo.co.in, laxprostho@yahoo.com

\section{ABSTRACT}

The problem of adjusting to old age in our modern society is becoming extremely difficult owing to the high values placed on youth, beauty and virility. For the aged themselves, these are frustrating years. They realize that they are beyond their productive peak and many of their ideas, goals, ambitions, hopes can never be attained. It is unfortunate that the geriatric patient generally needs most of the necessary dental and medical services at an age when he is least able to tolerate and afford them. The dental problems of geriatric patients present in the prosthodontic clinic differ because of the psychological factors always associated with them. The clinician should understand the psychological part of a dental problem of a geriatric patient because it always influences the decision making and treatment plan. An attempt has been made in this article to review these psychological factors and critically analyze their influence in dental treatment plan.

Keywords: Geriatric patient, Psychological factors, Treatment plan.
\end{abstract}

\section{INTRODUCTION}

Aging is associated with a decline in physical and mental health and vigor whose severity and rate of progression is subject to much variation. The psychological changes associated with aging were well described by Burdach (1819), as generally speaking, his (the old man's) susceptibilities are diminished both in range and degree. He is indifferent to much that interested him keenly in earlier life. His emotions are calmer and less frequent. His power of assimilating new ideas and of doing unaccustomed things is lessened. He easily forgets what he has recently experienced or what he himself has said or done. He takes longer to think anything out and like his power of intellectual assimilation, so his intellectual productivity is diminished.

The progressive decline of physical health and vitality and the accumulation of losses, deprivations and vicissitudes as age advances give rise to emotional disturbances in a relatively high proportion of the elderly. ${ }^{2}$ The psychological problems influencing the behavior of aging can be due to reactions to physiological changes or reactions to social changes.

\section{Physiologic Changes}

The changes influencing one's appearance, like loss of hair and face height, wrinkling of skin, changes in tooth appearance and loss of natural teeth seem to affect women more than men. Women frequently voice their concern while men may be more dramatic but concealed. In replacing the lost natural teeth with artificial ones, the dentist must be aware of this concern for appearance and strive to meet esthetic requirements of all patients.
- Patients in their late 40s, and early 50s, who insist that their natural teeth be removed because their position, relationship of the jaws, or the signs of age are distasteful to them, frequently result in an unfavorable manner to dentures. It is difficult to create beauty where beauty did not exist and have harmony with the surrounding environment.

- Women during and after menopause, particularly those who have been admired for their beauty, may be quite demanding about the cosmetic arrangement of their artificial teeth .They may blame the loss of their natural teeth on dentists. If they will not consent to a psychological evaluation and treatment, their dental problems may remain unsolved.

- The loss or decline of the senses of vision, hearing and taste has psychological implications. It can result in isolation causing personality changes, which may be resentful in nature.

- The loss of teeth coupled with the loss of the sense of taste and often a consequent appetite loss can contribute to deteriorating mental as well as physical disorders.

\section{Social Changes}

As a person ages, changes over which he has no control take place in his social life. Death claims relatives, friends and neighbors or they retire and move to a new location. Severance of these ties leads to isolation.

- Retirement can also lead to anxiety over loss of income and fear that they will have to depend upon someone else for support. The feeling of worthlessness, loss of identity and being rejected or forsaken can lead to the lack of desire to live. 
- Lonely patients can turn to the dentist for their never ending struggle against illness and old age. The dentist should encourage the patient to talk; more important, he should be willing to listen. A sympathetic word when inserting a denture into the mouth often does wonders. ${ }^{3,4}$

\section{REVIEW OF LITERATURE}

Progress in Gerontology has tended to push the shape of the survival curves of populations from the 'logarithmic' form to the more 'square' form (characteristic of population with a high standard of living). Social and medical progress produces this increasing 'squareness' in the survival curve. ${ }^{2}$

In the past, majority of these people were edentulous and used dental care infrequently. There is now ample evidence to show, that new elderly dental consumers have emerged to have a wider range of needs and expectations and demand a greater variety of services.

Patients seeking prosthodontic care arrive with an accumulation of experiences and resulting attitudes. In this context, MM House classified patients as philosophical, exacting, indifferent and hysterical.

The philosophical patient: This patient presents the best mental attitude for denture acceptance. This patient is rational, sensible, calm and composed in difficult situations. His motivation is generalized, as he desires dentures for the maintenance of health and appearance and feels that having teeth replaced is a normal, acceptable procedure.

The exacting patient: This patient may have all the good attributes of the philosophical patient; however he may require extreme care, effort and patience on the part of the dentist. This patient is methodical, precise and accurate and at times makes several demands.

The indifferent patient: This patient presents a questionable or unfavorable prognosis. He evidences little if any concern; he is apathetic and uninterested and lacks motivation. He pays no attention to instructions, will not cooperate and is prone to blame the dentist for poor dental health. A dental education program prior to treatment is recommended for this patient.

The hysterical patient: This patient is emotionally unstable, excitable, excessively apprehensive and hypertensive. The prognosis is often unfavorable and additional professional (psychiatric) help is required prior to and during treatment.,

Heartwell has grouped the aging into the realists, the resenters and the resigned.

The realists: These are the philosophical and exacting type. Have alertness to the changes and realism in accepting to enjoy their old age. They follow instructions, take pride in their appearance, and practice good oral hygiene, seek dental care and accept a proper diet.

The resenters: They are the indifferent and hysterical types. They resent and resist aging and consequently become psychologically involved. They will not listen to advice, rarely follow instructions, become negligent in oral care and rarely seek dental care. The psychologic change is one of involution, a reversal of development that is referred to as 'second childhood'. The concerned family members frequently seek treatment for them.

The resigned: They vary in their emotional and systemic status. The passive submission of this group does not always lead to successful prosthodontic results and is frustrating, not only to those responsible for their care but also to the dentist. ${ }^{3,4}$

Dr Suzanne Riechard has classified the elderly as (1957):

The mature group: Well-integrated persons with self awareness, satisfied people and are realistic, flexible and adaptive. Neither hostile nor do they repress hostility, open minded, self aware of growing old and accept the normal physiological changes .

The rocking chair group: Passive dependers that tend to lean on others for material and emotional support. Unambitious who find little satisfaction in work, impulsive and extravagant, have a tendency for excessive eating and drinking. Accept aging and look back on their lives with contentment.

The armored: Characterized by rigidity in character, work, principles of life. They are independent, participate actively in organizations and work hard as it keeps them well occupied. They have stereotyped thinking and counteract their fear of growing old by remaining active, self aware of their health but will not accept new treatment modalities, unless proven.

The angry men: Generally hostile, frustrated and blame others for failure. Pessimists and picture old age as a time of economic deprivation and virtual starvation. These people think in terms of ' black and white' or ' good' and 'bad' and not ready to accept reasons.

The self haters: These are people who are dejected of life and blame themselves for frustration and failures. These people characteristically turn aggression inward as self accusation and self blame.

The dentist may see patients with a variety of behavioral and mental disorders. The 4th edition of Diagnostic and Statistical Manual of Mental Disorders, Text Revision presents a classification system with which the dentist should be familiar to be able to understand psychiatric diagnoses and associated symptoms. This system consists of five axes/categories used to describe mental disorders.

\begin{tabular}{ll}
\hline Type & Description \\
\hline Axis I & $\begin{array}{l}\text { Clinical disorders; other conditions that may be a } \\
\text { focus of attention }\end{array}$ \\
Axis II & $\begin{array}{l}\text { Personality disorders; mental retardation } \\
\text { Axis III }\end{array}$ \\
Axis IV & $\begin{array}{l}\text { Peneral medical conditions } \\
\text { Axis V }\end{array}$ \\
\hline
\end{tabular}


The elderly population has a high prevalence of psychiatric complications associated with medical illnesses. About 15 to $20 \%$ suffers from depressive symptoms. Between 10 and 20\% suffer from anxiety disorders, including phobias. Phobia is the most common psychiatric disorder in women over the age of 65 years. Approx 20\% of the elderly have a substance abuse disorder.

The prevalence of dementia increases with age from $1 \%$ at age 60 to over $40 \%$ at age 85 . Overall the course of dementia is chronic in $65 \%$ of the cases, partially treatable in $25 \%$ of the cases and reversible in only $10 \%$ of the cases. Non-reversible dementia is seen in Alzheimer's disease, vascular dementia and in Parkinson's disease. ${ }^{9}$

Alzheimer's disease, first described by Alois Alzheimer in 1907 predominantly affects the elderly. There is recent memory loss or a change in personality or behavior. Slowly the cognitive problems start to interfere with daily activities. Anxiety and depression become more of a problem as the disease progresses. Delirium, commonly seen in the elderly, is primarily characterized by impaired attention and consciousness. Patients with delirium may appear withdrawn, agitated or psychotic. Patients with schizophrenia show psychotic symptoms consisting of delusions, hallucinations and incoherence. ${ }^{6}$

\section{DISCUSSION}

Because of the high degree of variability among elderly, each patient must be treated individually in terms of needs, wants and desires. The dentist must understand how to deal with psychologic problems, as well as the dental problems of his patients. This is not to be interpreted that the dentist should be substituted for a psychiatrist, but rather he should counsel the patient and members of his family and when necessary refer them for psychiatric consultation.

- A dentist should know what behavior or personality changes occur with aging and recognize them during his clinical examination of the patient.

- Shaking hands with a patient may reveal much about the emotional state of the patient at the time of the dental visit. The dead fish handshake might indicate an uncooperative patient without too much interest. A vise-like grip could be introducing an insecure patient. The patient with sweaty, clammy and cold hands is likely to be anxious about the impending dental work. The patient offering a normal, firm handshake would probably be the easiest to get along with.

- The best preoperative measurement of anxiety can be found out by the dental anxiety scale (DAS) introduced in 1969 or the revised scale published in $1994 .^{5}$

- Most depressed patients may be best managed by dealing with their immediate dental needs only during the depression. Once the patient has responded to the medical treatment, more complex dental procedures can be performed. $^{6}$
- Schizophrenic patients should always be accompanied by an attender or family member. Patients should be scheduled for morning appointments. Confrontation and authoritative attitude on the part of the dentist should be avoided. If such an approach does not allow for proper dental treatment, sedation or tranquilization should be used. ${ }^{6}$

- Patients with Alzheimer's, dementia often misplace, lose or wear their prosthesis improperly. They are managed best by an understanding and empathetic approach. Adjustment of prostheses is usually the treatment of choice. ${ }^{6}$

Patient's gagging history should also be noted. In some patients, it may be active to the point where prosthodontic treatment may be compromised. It could be due to systemic disorders, psychological factors, extraoral and intraoral physiological factors and iatrogenic factors. Fortunately, the management of the gag reflex is not difficult and the dentist should not increase patient's awareness of the problem.

\section{Dental Management of Anxious Patient ${ }^{6}$}

\begin{tabular}{|c|c|c|}
\hline & Status & Management \\
\hline \multirow[t]{2}{*}{ 1. Preoperative } & a. Behavioral & $\begin{array}{l}\text { - Effective } \\
\text { communication } \\
\text { - Explanation of } \\
\text { procedures } \\
\text { - Make the patient relax }\end{array}$ \\
\hline & b. Pharmacologic & - Oral sedation \\
\hline \multirow[t]{2}{*}{ 2. Operative } & a. Behavioral & $\begin{array}{l}\text { - Answering patient's } \\
\text { questions } \\
\text { - Reassurance }\end{array}$ \\
\hline & b. Pharmacologic & $\begin{array}{l}\text { - Effective local } \\
\text { anesthesia } \\
\text { - Oral sedation }\end{array}$ \\
\hline \multirow[t]{2}{*}{ 3. Postoperative } & a. Behavioral & $\begin{array}{l}\text { - Instructions to patient } \\
\text { - Description of } \\
\text { complications }\end{array}$ \\
\hline & b. Pharmacologic & $\begin{array}{l}\text { - Analgesics, adjunctive } \\
\text { medications }\end{array}$ \\
\hline
\end{tabular}

\section{Dental Management of Depressed Patient ${ }^{8,10}$}

\begin{tabular}{|c|c|c|}
\hline & Status & Management \\
\hline & Preoperative & $\begin{array}{l}\text { - Consultation with physician } \\
\text { - Examination of signs } \\
\text { - Abrasion of teeth } \\
\text { - Gingival injury } \\
\text { - Throstomia } \\
\text { - Leukombocytopenia }\end{array}$ \\
\hline 2. & Operative & - Care with use of local anesthetic \\
\hline & Postoperative & $\begin{array}{l}\text { - Avoid/reduce dosage of sedatives/ } \\
\text { narcotics } \\
\text { - Management of xerostomia }\end{array}$ \\
\hline
\end{tabular}

Prosthodontic treatment is best for the Realist group while palliative treatment is advisable for the Resenters group. 
Treatment for the resigned group may be definitive or palliative in nature. Two or more treatment plan options should be presented to the patient along with advantages, disadvantages, fees and time required for each plan. Gordon proposed a treatment planning model for use with compromised elderly that emphasized the contribution of various 'modifying factors'. These include quality of life, prognosis without treatment, patient attitude, iatrogenic potential, duration of treatment, repair potential, dentist limitations, flexibility of the proposed treatment, benefits versus cost and risk, and patient and family preferences. $^{5}$

\section{Treatment Planning Worksheet}

\begin{tabular}{ll}
\hline $\begin{array}{l}\text { Problem list } \\
1 .\end{array}$ & (List here diagnoses) \\
2. & \\
3. & (Explains to the patient what \\
the dentist is aiming for)
\end{tabular}

Dentures should not be constructed if a patient is under extreme physical or mental stress. A patient with advanced degenerative disease is no candidate for complete denture. The geriatric patient can usually be grouped into three categories with respect to attitude towards dentures:

The satisfied wearer of old dentures: Inspite of lack of retention and stability as well as lack of vertical dimension and colossal problems, these patients are satisfied with their old dentures. It is an error to try to talk these patients into having new dentures constructed. The only time the patient must be overruled is when severe tissue deterioration has occurred that is directly related to the old dentures.

The geriatric patient who does not want dentures: These patients have continued satisfactorily without dentures and are content to remain edentulous. If facial appearance is unimportant to these patients and being without teeth does not alter their personalities, it is an error to try to convince them to have complete dentures constructed.

The geriatric prosthodontic patient: The patient must be educated to understand and accept the reduced efficiency of the artificial dentures.
Visits should be carefully planned to be short, with a maximum amount of work completed during the scheduled time. Morning appointments can be advantageous because the geriatric patient usually has less tissue distortion early in the day. Geriatric patient should not be promised too much. If the prosthesis does not turn out to be everything the dentist said it would, the aged patient will be extremely disappointed. The treatment plan should be discussed and understood by the patient's family or spouse.

Even when the loss of all the remaining natural teeth is inevitable, the dentist is often too quick in diagnosing complete dentures. Partial, transitional or overdentures is usually the treatment of choice. It is better to retain natural teeth for as long as possible. ${ }^{1}$ The prognosis of prosthodontic treatment also depends on the psychological status of the patient.

\begin{tabular}{ll}
\hline Excellent prognosis & Poor prognosis \\
\hline 1. Not demanding/exacting. & Demanding and exacting. \\
Quite accommodating & Pays attention to small details \\
2. Well-balanced lifestyle. & Preoccupied with denture \\
Not preoccupied with & problems. Has consulted \\
denture problems & several other dentists \\
3. Motivated to succeed with & Poorly motivated to succeed \\
dentures & with dentures \\
\hline
\end{tabular}

\section{CONCLUSION}

The elderly have both the greatest level of need for prosthodontic services and the greatest degree of complicating psychological factors. The emotional and psychologic makeup of the geriatric patient must be kept in mind during the entire procedure. Success in geriatric dentistry can be the result of building up the patient's confidence in the dentist, regardless of the quality of the final prosthesis.

\section{REFERENCES}

1. Sheldon Winkler. The geriatric complete denture patient: Winkler S (Ed). Essentials of complete denture prosthodontics (2nd ed). Ishiyaku Euro America Inc. USA 2000;441-55.

2. Comfort A. Ageing and mental diseases of the aged: Slater E, Roth M (Eds). Clinical Psychiatry (3rd ed), UK: Bailliere Tindall 2001;535-36.

3. Heartwell CM, Grieder A, Giddon D, Collett H, Jankelson B. Syllabus of complete dentures (4th ed), Pennsylvania: Lea and Febiger 1992;106-36.

4. Chaytor D. Diagnosis and treatment planning for edentulous or potentially edentulous patients. In: Zarb, Bolender (Eds). Prosthodontic treatment for edentulous patients (12th ed), St Louis: Elsevier 2004;75-76.

5. Busschots G, Milzman B. Contributers: Basi D, Bordon E, Bordon J, Bullock K, Busschots G, Emery R, et al. Dental patients with neurologic and psychiatric concerns. The dental clinics of North America 1999;43:471-83.

6. Zwetchkenbaum S, Shay K. Contributers: Berg R, Cancro J, Carter P, Casino A, Erickson L, Ettinger R, et al. Prosthodontic considerations for the older patient. The Dental Clinics of North America 1997;41:817-46. 
7. Johnson T, Shuman S, Ofstehage J. Contributers: Berg R, Cancro J, Carter P, Casino A, Erickson L, Ettinger R, et al. Treatment planning in the geriatric dental patient. The dental clinics of North America 1997;41:945-58.

8. Diagnostic and statistical manual of mental disorders (DSM IV) (4th ed), Washington DC 1994 American Psychiatric Association.

9. Association AP. DSM-IV Classification. In diagnostic and statistical manual of mental disorders - text revision
(DSM-IV - TR) (4th ed), Washington DC 2000, American Psychiatric Association.

10. Goldberg RJ, Horwath E Courinos, Friedlander AH, Bird TD, Feinstein RE, Bazin N, Fremont P, Mitchell RJ, Magarian GJ, Middaugh DA. Behavioral and psychiatric disorders. In: Little J, Falace D, Miller C, Rhodus N (Eds). Dental management of the medically compromised patient (6th ed). St Louis: Mosby 2002;439-78. 